\title{
The Gameplay Loop Methodology as a Tool for Educational Game Design
}

\author{
André Czauderna and Emmanuel Guardiola \\ Cologne Game Lab, TH Köln, Cologne, Germany \\ ac@colognegamelab.de \\ eg@colognegamelab.de \\ DOI: 10.34190/JEL.17.3.004
}

\begin{abstract}
The field of game design for educational content lacks a focus on methodologies that merge gameplay and learning. Existing methodologies typically fall short in three ways: they neglect the unfolding of gameplay through players' actions over a short period of time as a significant unit of analysis; they lack a common consideration of game and learning mechanics; and they falsely separate the acts of playing and learning. This paper recommends the gameplay loop methodology as a valuable tool for educational game design, as it addresses these major shortcomings. Furthermore, this paper outlines how this methodology can be supported by knowledge from subject-specific didactics-considering both the curriculum and its mediation (contributed by experts from educational practice) as well as methods of player-centered design-in order to ensure the appropriateness of learning objectives and techniques of mediation in the context of a particular field of knowledge, the game's appeal to its target group, and the effectiveness of the learning mechanics. A case study of the design and production phases of Antura and the Letters, a literacy game for Arabic refugee children, illustrates the uses of the gameplay loop methodology situated in the described broader approach to educational game design. Finally, this paper explains the results of an impact study revealing that the approach indeed provides the opportunity to merge playing and learning.
\end{abstract}

Keywords: serious games, educational games, instructional design, game design, gameplay loop, player-centered design.

\section{Educational game design: A merging of game and instructional design}

The design of educational games is a complex endeavor because educational games are expected to fulfil two requirements, which at first seem contradictory: educational games should be as appealing as commercial, offthe-shelf games designed solely for entertainment, and they should provide their players with a learning experience related to educational domains beyond the game itself. Consequently, the design of educational games must be informed by two different disciplines-game design and instructional design-that bring different histories and approaches to the table (Becker, 2016). In our opinion, the successful design of educational games presupposes a significant merging of both disciplines, in other words, a formal approach combining game and instructional design (see Buchanan, Wolanczyk and Zinghini, 2011).

In response to the aforementioned requirement as well as to massive growth in serious game production in general and educational game production in particular, ideas from game design and instructional design were synthesized to form a new field, more specifically, (inter)discipline that is usually called "Serious Game Design" or "Educational Game Design". ${ }^{1}$ Lameras et al. (2017, p. 972) describe serious game design as "a relatively new discipline that couples learning design with game features" and state that "[a] key characteristic of this approach is grounded in educational need and theory, rather than a focus purely on entertainment".

In this field, it is undisputed that serious game design poses different challenges from entertainment game design and requires a unique methodology that addresses both instructional strategies and learning theories. Gunter, Kenny and Vick (2006), for instance, assume that "[t]he goal of serious game design is similar in nature to that of entertainment games, but is more complex, in that not only must one maintain intellectual control of the design elements that lead to a fun and engaging game, but one must also plan instructional elements that lead to a fun, engaging, and educational game experience". The authors argue consequently that "instructional strategies and learning theories must be included" (ibid.) in the formal methods of serious game design. Accordingly, in recent years, many authors have suggested formal design patterns, frameworks, and

\footnotetext{
${ }^{1}$ We define serious games as all digital games acting as more than entertainment, including not only educational games, but also games for health, advergames, etc., whereas we define "educational games" as all digital games that are explicitly designed for educational purposes in formal, non-formal, and informal learning contexts. In this paper, we are concerned with the design of educational games in particular instead of serious games in general. However, we are aware that the majority of available literature relevant for our research and development project employs the broader term "serious games" in reference to "educational games". Therefore, we will use the term "serious games" whenever we refer to this literature, as well as to the broader category.
} 
methodologies to offer guidelines for the design of serious games. As most of them were developed in academia (which is closely connected to the relatively small serious game industry), many are more abstract and less practical than traditional game design methodologies, which were developed inside the gaming industry and are thus more strongly influenced by its market-driven logic of immediate application.

Despite major achievements inside the academic field of serious game design, for example Arnab and Clarke (2016, p. 279), assessing the theory and practice of serious game design, still assume the following: "The development of these games does not normally follow a specific set of guidelines or process, which makes them more bespoke and less replicable. Moreover, existing frameworks or guidelines are often high-level and/or theoretical design models that provide general design considerations rather than a prescribed development process".

It can be concluded that there is still a high demand for new methodologies for the design of serious games, and particularly educational games. In the present paper we will thus introduce the gameplay loop methodology as a valuable tool for educational game design.

Next, we will offer a closer look at existing approaches to the design of serious games in order to highlight their shortcomings with regard to educational games. At the end of this section, we will outline our research question and design. We will then explain our broader approach to educational game design, in which the gameplay loop methodology is situated. Afterwards, we will more closely emphasize the gameplay loop methodology as a necessary technique for designing educational games. Thereby, we address the identified gap in the literature on methodologies for the design of educational games. The application of the gameplay loop methodology will be illustrated through a case study of the design and production of Antura and the Letters, a literacy game for Arabic-speaking refugee children. Finally, we will summarize results of an impact study showing that our approach is able to initiate a unification of playing and learning. We will close the paper with a discussion as well as a conclusion.

\section{An analysis of existing serious game design methodologies}

In recent years, the number of papers proposing methodologies for the design, analysis, and evaluation of serious games, including educational games, has increased tremendously (see Ávila-Pesántez, Rivera and Alban, 2017 for an overview). After reviewing the current body of serious game design literature and focusing on the methodologies' value for the design of educational games, we have concluded that most approaches favor a bird's eye view of games and their overall design, more specifically their various features, over a closer, more detailed perspective of gameplay and learning possibilities. Learning objectives, for instance, are rarely considered throughout each stage of design, let alone associated with game mechanics and/or gameplay.

Consequently, we argue that many approaches lack a significant merging of game design and instructional design.

Important contributions to the field of serious game design include de Freitas and Oliver's (2006) fourdimensional framework (4DF model) and Mitgutsch and Alvarado's (2012) Serious Game Design Assessment Framework (SGDA Framework). De Freitas and Oliver suggest that developers consider context, learners, pedagogy, and representation for the design and evaluation of serious games; Mitgutsch and Alvarado (2012) relate the purpose of the game to game mechanics; framing; content and information; fiction and narrative; aesthetics and graphics; and coherence and cohesiveness of the game system. Although both frameworks are based on a holistic design approach, offer useful guidance for the design of well-rounded educational games that motivate players, and include learning possibilities, they, like many other approaches to serious game design, do not emphasize the actual processes of learning enough-which should be of particular importance in the development of educational games.

Other approaches such as Gunter, Kenny and Vick (2006), Winn (2008), and Becker (2011) consider learning more directly. According to Buchanan, Wolanczyk and Zinghini (2011: ch. 3.2), the integration of learning objectives into the approaches of the field "ranges from a mere suggestion to a core principle of the framework's design approach". Unfortunately, many of these approaches lack an adequate appreciation of the procedural nature of learning as well as a proper consideration of the relationship between learning mechanics and game mechanics. Furthermore, they neglect-as others have pointed out before-“the actual design 
process and methodology" (Arnab and Clarke 2016, p. 282), i.e. the "how to" (ibid). Instead, they offer rather general descriptions and heuristics about what constitutes a good educational game (ibid).

Pattern-based approaches aim at an integration of educational and game design principles (see Kiili 2010; Kelle, Klemke and Specht 2011). According to Kiili (2010, p. 299), learning game design patterns "are descriptions of commonly reoccurring parts of the design of a learning-game that concern and optimize gameplay from an educational perspective" (ibid). Carvalho et al. (2015, p. 169), however, debate that the libraries of patterns identified by these kinds of approaches "neither offer the classification of individual components [of the game] nor an account of the relationship between them".

Assessing the field in general, many authors indicate the missing "analysis of the relationships between game mechanics and learning constructs" (Arnab et al., 2015, p. 394), which is seen as "a key factor in game design for learning" (Arnab et al., 2015, p. 394). Lameras et al. (2017, p. 973), for instance, highlight that "[t]here are no pedagogically driven strategies that take into account how learning attributes are interlinked to game elements for balancing learning with play". According to these authors, "[t]his is due to a limited evidence base of comparative evaluations assessing differing game designs against a single pedagogical model or vice versa" (ibid).

The Learning Mechanics-Game Mechanics (LM-GM) model by Lim et al. closes this gap as it maps aspects of learning and instruction to game mechanics: "To map pedagogical constructs to entertaining gameplay, Lim et al. (2013) proposed the LM-GM and was evaluated by Arnab et al. (2015) as an SG analysis guideline with positive outcomes. As a general overview, the pedagogical elements are viewed as an abstract interface while game elements are deemed as a concrete interface of SGs. This means that pedagogy and its methods are abstract (theoretical and conceptual), while game mechanics are concrete, i.e., by rules or algorithms" (Arnab and Clarke, 2016, p. 286).

The model shifts the focus of serious game design to game mechanics, which too often have been neglected in the literature on serious game design methodologies. This shift is insofar overdue and of particular importance as the majority of the academic serious games community's theories assume that game mechanics are a key factor for the successful initiation of learning. Arnab et al. (2015, p. 396) argue as follows: "In SGs, game play should support intrinsic experiential learning. It is therefore reasonable to postulate that knowledge acquisition and skill training should be obtained through game mechanics (e.g., quests, cascading information, leader boards, goals, levels, badges, role-play, tokens, etc.)-and not, for instance, from related user manuals. Thus, we tried to investigate how to establish relationships between the mechanics present in educational philosophies (pedagogical theories and strategies) and those of games". However, as Carvalho et al. (2015, p. 169) point out, LM-GM is limited as it "does not expose the connection between concrete mechanics and the high-level educational objectives that the game is supposed to attain".

Despite significant progress achieved through the models mentioned above, it should be emphasized that they "do not cater for presenting formulaic strategies or methodologies" (Arnab and Clarke, 2016, p. 282). Therefore, applied methodologies that offer concrete guidance for educational game design are still urgently needed.

In addition to the criticisms raised by Arnab et al. (2015), it should be mentioned that overall too many approaches model learning solely as a result of gameplay and thus reduce it to learning outcomes. These approaches do neither take into account that playing and learning are highly interconnected categories of analysis, nor that learning in general must be seen as a process (Gee, 2003). Furthermore, players' actions are not assessed individually, such that each action that a player executes is examined for its contribution to the whole learning experience. Instead, players' actions are observed rather superficially, over the course of a single session, or multiple sessions. Thus, most approaches lack a micro-perspective of players', or more specifically learners' actions in sequence - including their learning potentials (while taking into account the challenges of the game).

Considering major shortcomings of the methodologies mentioned above-including the neglect of the unfolding of gameplay through players' actions over a short period of time as a unit of analysis; the lack of a common consideration of game mechanics and learning mechanics; and the false separation of playing and 
learning - this paper suggests the gameplay loop methodology (Guardiola, 2016) as a valuable tool for the design of game-based learning.

This methodology is situated in a broader approach to educational game design which does not only imply the application of player-centered design methods, but also the consideration of domain-specific didactics, the latter being neglected in many existing educational game design methodologies as well.

The study reported in this paper applies an exploratory qualitative research design based on a single case that exemplifies the application of the methodology. In the presented case study, the paper demonstrates how the gameplay loop methodology has been successfully used to design an educational game which consists of a series of meaningfully connected mini-games and relies on cognitive theories of learning. In addition to the case study reflecting on the design process, the paper provides evidence from an impact study by Koval-Saifi and Plass (2018), which reveals that the approach can actually lead to significant learning outcomes.

By exemplifying the application of the gameplay loop methodology and comparing it to other approaches, the paper answers the following research question which is highly relevant for applied educational game design research: How does the gameplay loop methodology facilitate the design of educational games that initiate a unification of playing and learning?

\section{The gameplay loop methodology as the central part of a broader approach to educational game design}

Before providing a detailed exemplification of the gameplay loop methodology as a tool of educational game design (in section 4), we will situate the methodology in our broader approach to educational game design, as applied in the design and development of Antura and the Letters.

\subsection{The gameplay loop methodology as a tool for entertainment and educational game design}

The gameplay loop methodology comes from the entertainment game industry, used during the early stages of a production, in particular during the concept phase and pre-production. The goal is to formalize the player experience called gameplay. Gameplay refers to the sum of actions and activities performed by the player interacting with the game, trying to solve the uncertain situation he or she is engaged in. Formal representations of gameplay, such as the gameplay loop, emerged from this often collaborative practical design task and the need to document it. Guardiola (2016) describes and models this method in order to facilitate its use for design, teaching, and analysis.

The method consists of listing a certain number of player actions, represented by verbs and minimal context. These sparse depictions of action are then connected in the form of a flow chart. During the design process, the objective is to formalize the core gameplay of the game, or multiple gameplays, using these flow charts, and use them to determine what sorts of challenges these actions might present to players and determine what kinds of abilities are required to complete these tasks.

One of the characteristics of this method is the possibility to represent all the types of actions or activities that the player executes, for example, actions that have an immediate, measurable effect on the virtual world, such as pressing a button, as well as actions outside of the game, for instance planning something. Applied to the game-based learning field, the gameplay loop helps to visualize the different types of abilities that learners use to solve a situation and determine whether the actions that constitute a specific gameplay contribute to pedagogical and/or entertainment content.

\subsection{Antura and the Letters' experimental context}

Antura and the Letters (Cologne Game Lab/TH Köln, Video Games Without Borders and Wixel Studios, 2017) is an educational and humanitarian research project led since 2016 by the Cologne Game Lab of TH Köln, in collaboration with the non-profit organization Video Games Without Borders and the Lebanese game company Wixel Studios. Antura is an educational mobile game addressing mainly five- to ten-year-old Syrian child refugees in the Middle East. Due to the Syrian conflict, nearly three million children have dropped out of school or are in precarious educational situations. The pedagogical goal of the game is to help players acquire the most basic skills of literacy: Arabic letters, spelling, and some vocabulary. The project was funded through 
prize money from the international contest EduApp4Syria, organized by the Norwegian Ministry of Foreign Affairs. Antura is an open source project.

Most of the development team was composed of experienced game developers from the industry who have more experience developing entertainment content than educational content. The pedagogical content was developed in collaboration with Arabic literacy experts and Syrian elementary school teachers. The concept phase started in February 2016. Pre-production took place between May and August 2016, and main production continued until March 2017, when the open beta was released on major mobile app stores. The beta version was used for a large impact evaluation in refugee camps in Jordan (see section 5). The game is free and currently available worldwide on mobile and on PC. By January 2019 Antura had reached over 120,000 users across all platforms.

\subsection{Our general approach to educational game design: The gameplay loop methodology, subject- specific didactics, player-centered game design}

From the start, Antura and the Letters aimed to be a game in the fullest sense. Thus, the approach was not to try to create cosmetic, overly explicit pedagogical activities, but to take all the benefits of a real play experience. Our objective was to trigger principles such as flow, engagement, and motivation, as they would emerge from a purely entertainment-oriented game. Our work on the narrative context, the game mechanics, the signs and feedbacks, the reward system and all other aspects of the content were directly influenced by empirical practices from the entertainment industry.

In the game, the player is tasked with helping the keeper to watch over wild little creatures called the Living Letters. The player explores several environments on a step by step walkthrough. Antura is the clumsy keeper's dog, helping through each mission. At each step in the game the player must play several mini-games involving some of the Living Letters and Antura the dog. Each of these mini-games is designed to present the player with a challenge connected to a specific pedagogical goal.

\subsubsection{Overview of our design approach}

Overall, our design approach consists of the following structural elements: (a) consideration of knowledge from subject-specific didactics in terms of the curriculum (learning objectives) as well as its mediation (appropriate teaching methods), i.e., in our case Arabic language pedagogy provided by Arabic literacy experts and Syrian elementary school teachers, (b) the gameplay loop methodology as such, (c) methods from playercentered game design.

The gameplay loop methodology (b) stands in the center of our approach. By applying this methodology, learning mechanics are designed, i.e., learning opportunities are implemented into the game. Thereby, the methodology aims to merge playing and learning. The other structural elements support this very process. While (a) ensures the pertinence of learning objectives and methods of mediation in the context of a particular field of knowledge, (c) influences the game's appeal to the target group and the effectiveness of the learning mechanics.

All of the above-mentioned structural elements are embedded in an overall iterative design process (figure 1). During our concept and pre-production phases, we defined a set of learning objectives and teaching methods based on Arabic language pedagogy and considered the target group (element a), and thereafter integrated these micro-pedagogical objectives into the game by using the gameplay loop methodology (element b). Afterwards, we applied methods from player-centered design to evaluate the goals of our design process to improve our prototype's qualities as both a game and learning tool (element c). Next, we returned to element $a$ and $b$, and so on. The relationship between the structural elements is circular. We applied this iterative design process most intensively during the concept and pre-production phases, but also used it occasionally in the production phase. 


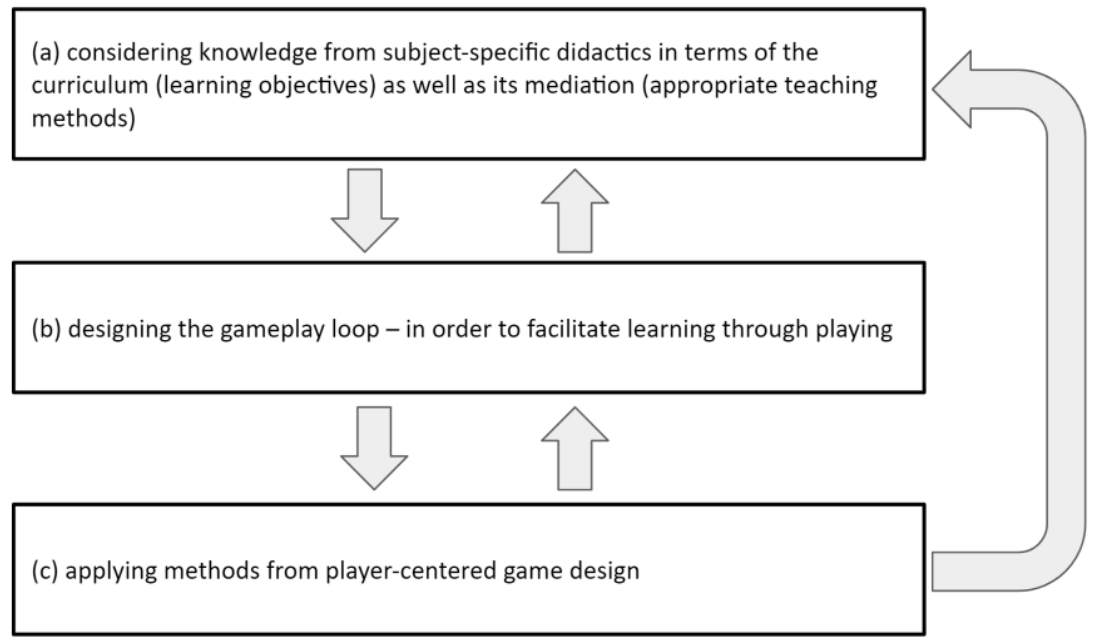

Figure 1: Our iterative process with three layers of design

Preceding a detailed description of the gameplay loop methodology as such (element b) in the next section, we will briefly outline our way of using subject-specific didactics (element a) and player-centered game design (element c).

\subsubsection{Subject-specific didactics}

Subjects such as math, geography, and languages follow their own didactics concerning their curricula (what should be learned) and their mediation, i.e. teaching methods (how can learning be initiated). During the concept and pre-production phases of Antura and the Letters, we worked with Arabic literacy experts and Syrian elementary school teachers to determine learning objectives and subject-appropriate teaching methods from non-game contexts that may be translated into a game context.

The experts and teachers' first task was to create a finite list of micro-pedagogical objectives that were linked to the process of learning the alphabet and the various forms of its letters, reading and spelling principles, acquisition of new vocabulary and eventually reading fluency. We identified a group of 19 micro objectives. In figure 2, which is an extract from an early design document, you can see the micro objectives on the top of the table, in each column. Each of them covers a precise topic. For instance, the goal could be to deal with "one letter" and to focus on "the name of the letter", "the pronunciation" or the "shape" of it. We added a twentieth objective for "unique objectives".

During the design process in the concept and pre-production phases, we managed to create many mini-games, with gameplays that permit all of the micro pedagogical goals. For the team, this table was a way to check if we had covered them all. Each row is dedicated to a mini-game and shows the intended pedagogic effect. When the cell in the row contains a " $X$ " or " $X X$ ", it means that the core gameplay of the mini-game addresses this pedagogical objective. Sometimes we also expect pedagogical impacts simply by the way the game is introduced or by the way it gives feedback to the player. For instance, one mini-game is introduced by the voice of a character asking the player to find the letter Alif while showing the shape briefly. This introduction in of itself has also a pedagogical value. We reference these side effects as "intro", "result", "feedback" depending in which stage of the mini-game this reinforcement happens.

We initially planned to have several mini-games working toward the same pedagogical goal so that we may provide variety in the player experience. Our first design listed 40 mini-games, 22 unique gameplays and 18 additional variations. For instance, the gameplay of the mini-game Balloon - Letter in a word was planned to be reused for variations Balloon - Spelling or Balloon - Word Image (vocabulary oriented). We designed each of the mini-games on paper at this stage, using the gameplay loop approach, as it is detailed in section 4 . For production reasons, we had to reduce the total mini-games to 30, composed of 17 different gameplays and 13 variations. After the release of the beta version and multiple playtests, we again reduced the number of games to a total of 24 (13 gameplays plus 11 variations), keeping and improving the most efficient ones. 


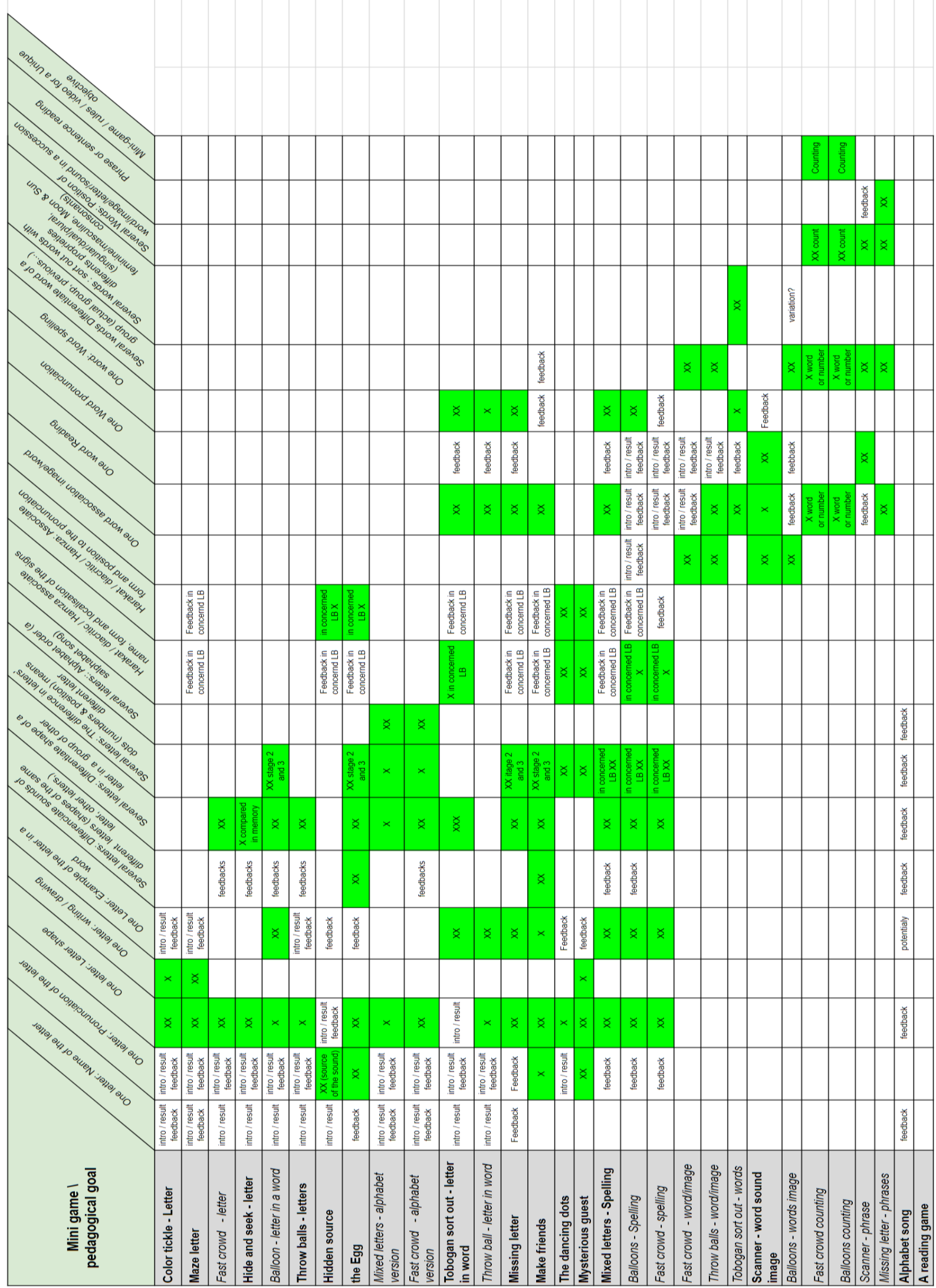

Figure 2: Extract from our design document, the table of mini-games per micro pedagogical goals 


\subsubsection{Player-centered game design}

Player-centered game design is a widely used practice in today's game development. Its iterative design process is applied all throughout the medium, from huge AAA productions, to small indie projects, to game design education. Approaches to player-centered game design are related to and inspired by the tradition and practices of user-centered design (see Norman 1990). However, Hodent (2017) argues that games must not only be "usable", but also "engage-able". Thus, her approach introduces the concept of "engage-ability" to player-centered game design, while maintaining the significance of the well-established concept of "usability".

The concept of "engage-ability" is supported by the core pillar of "motivation" (considering players' needs for competence, autonomy, and relatedness), which is supported by the pillars of "game flow" - a state of enjoyment-and "emotion" - the game feel (ibid.: p. 137). Player-centered game design, then, should ensure that games are easy to learn, fun to play, emotionally appealing, and able to keep players motivated, which includes allowing them to experience a state of "flow" (Csikszentmihalyi, 1990) over and over again (see Fullerton, 2014; Salen and Zimmerman, 2003). For this purpose, player centered design applies methods of social research such as focus groups, observations, or analytics (tracking in-game player behavior). The results are subsequently used to improve the game. Afterwards, another collection of data takes place, and so on. This iterative design process is repeated until the best possible outcome has been reached.

Arguably, it is more important to consider the player's perspective in the field of educational game design than in other game design contexts. Educational games are generally designed for a broader target group than many entertainment games (e.g. educational games that are designed for a school context) and thus they must not take entertainment games' standard of game literacy for granted. At the same time, other games are designed for very specific audiences (e.g. games for groups of people with certain restrictions, such as a disability), whose general game literacy remains unexplored. Thus, it seems to be more difficult for educational game designers to meet their players' preferences and needs. Hence, early playtesting with members of the target audience is a key step in making educational games accessible, usable, and appealing. This becomes more complicated when we consider the fact that it is not sufficient for educational games to be simply accessible, usable, and appealing; they also must fulfill their educational objectives. In other words, they must enable players to gain knowledge and/or skills. Therefore, in iterative player-centered educational game development, the evaluation of the educational impact is of paramount importance.

Throughout the design and development of Antura and the Letters we used a variety of methods, such as focus groups, persona, and analytics, to evaluate various prototypes of the game. Major lessons we have learned that have allowed us to improve the game do not only concern the game's appeal to the target group, but also its general didactical approach as well as the relationship of playing and learning in several gameplay loops.

For instance, we switched to a more phoneme-based approach in the game, instead of a letter-based approach. Children now learn a few letters and start to read simple words relatively quickly, instead of learning the entire alphabet first. This enables children to see the utility of what they are learning sooner. It also reduces the game's duration, which was too long in the first version, causing children to lose motivation to complete the game. When it comes to gameplay loops, our player-centered approach led to an easing of difficulty and a closer relationship between playing and learning in several cases (see examples below and in Guardiola, Czauderna and Samur, 2019).

In the following section, we will finally discuss the application of the gameplay loop methodology as a valuable tool for educational game design.

\section{The application of the gameplay loop methodology in the design of Antura and the Letters}

The gameplay loop methodology was applied during the design of the mini-games. For each mini-game, we formalized a gameplay loop, incorporating every type of action that the player would have to perform to achieve their goal. Initially, we tried to separate the formal aspect of the action blocks in the flow chart to have a better reading of the types of challenges facing the player: Orange for actions that implied pedagogical challenges; blue for actions that did not imply pedagogical challenges, including, but not limited to, purely ludic ones. 
Figure 3 is extracted from the initial game design document created during the pre-production phase. It describes the mini game Throw Ball. The player sees several Living Letters in a landscape, hears the name of a letter, and must throw a ball to the named letter, as in the capture sequence of the mobile game Pokémon Go (Niantic, 2016).

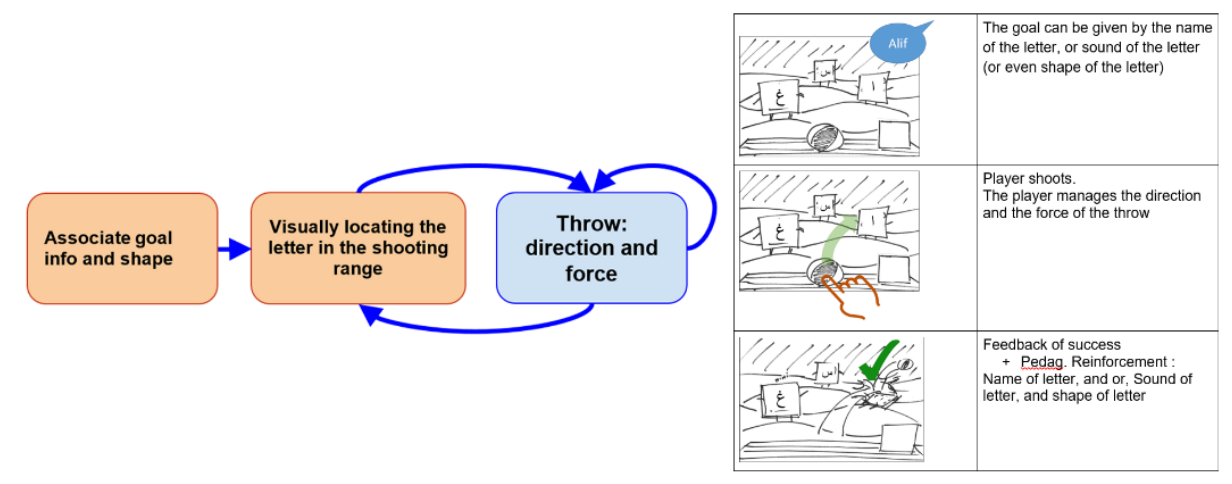

Figure 3: Gameplay loop (left) and storyboard (right) of the mini-game Throw Ball

Figure 3 (left) shows the first gameplay loop completed for this game, using the color code we set. In this example, we can easily determine which actions are pedagogical (associate goal info and shape on screen, and locating the letter on screen) and which fulfil purely entertainment related functions (aiming and throwing). It was not, however, always so clear. Each mini game was also illustrated in the form of a storyboard depicting one round of gameplay.

For the mini-game Maze (figure 4), we were not able to distinguish purely entertainment-oriented actions from pedagogical actions. The player has to draw a line with her finger along a track, which a racing rocket will follow. The track itself has been illustrated in the shape of the letter being learned. In fact, it seems that all actions embody pedagogical components, but, at the same time, challenge the player with other abilities, such as hand-eye coordination in order to remain in the track.
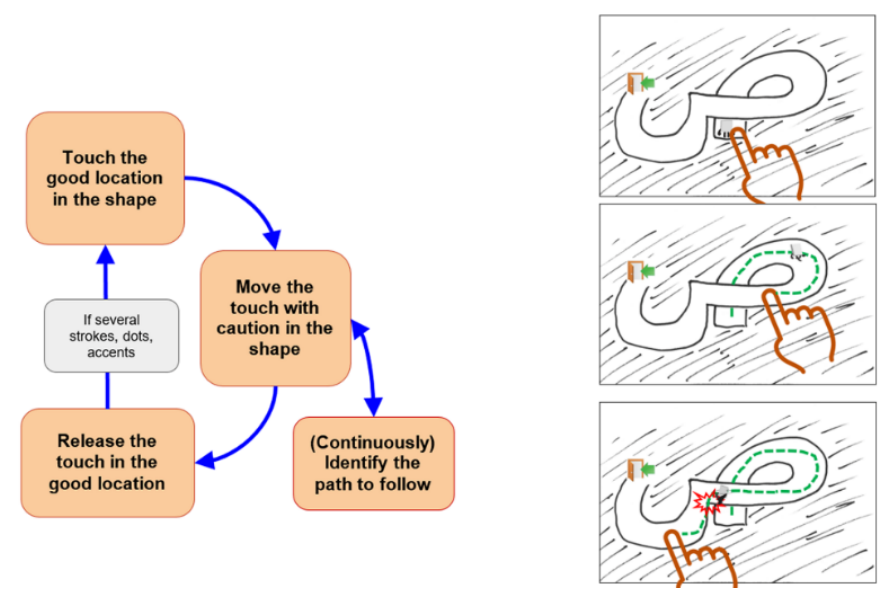

Figure 4: Gameplay loop (left) and storyboard (right) of the mini-game Maze (extracts from the briefing document in pre-production)

Using the gameplay loop during the concept phase also helped us to determine that some mini-games did not have an equilibrium between pedagogical and entertainment challenges. For instance, in Make Friends (figure $5)$, the player has to find the common letter in two words. These words, living creatures in Antura, get angry with each other. When the player finds the common letter, the Living Words are reconciled. 

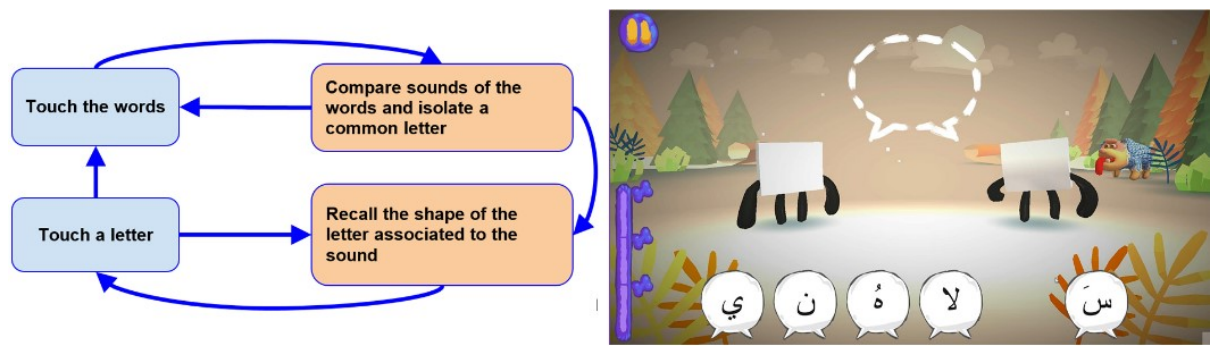

Figure 5: Initial gameplay loop (left) and screenshot (right) of the mini-game Make Friends

In this example (figure 5 left) the gameplay loop shows that the non-pedagogical actions, in blue, are not really ludic. The player simply touches an item on screen without any real ludic challenge. In Make Friends, no abilities apart from the pedagogical ones seem to be challenged. In spite of this, in the context of the production, we kept this mini-game, betting on other aspects to please the children. For example, players might be more focused on the narrative context of reconciliation between two angry Living Words, the animation and behavior of the angry Living Words, or the joy of seeing the Living Words become friends again than on the actual mechanics of the mini-game.

All previous examples come from initial briefings in the concept and pre-production phases. As the development team started to produce the game, we had to modify the gameplay of several mini-games. This iterative design process is a normal process in game production. These modifications impacted the gameplay loops.

The mini-game Throw Ball was problematic: in the first prototype playtest, the children in the test group had issues aiming at the Living Letters properly with the ball. The throwing mechanic on a horizontal screen was not as enjoyable on a vertical screen as it was in Pokémon Go (Niantic, 2016), for example. However, we had to use the horizontal format for Throw Ball, because in Antura, all activities, menus, visual content, and all other mini-games used this screen position. Thus, the team proposed modifying the gameplay by introducing a slingshot (figure 6 right). As soon as the game designer proposed the modification, the gameplay loop was modified (figure 6 left) and the potential effect on the learning/ludic actions was shown.
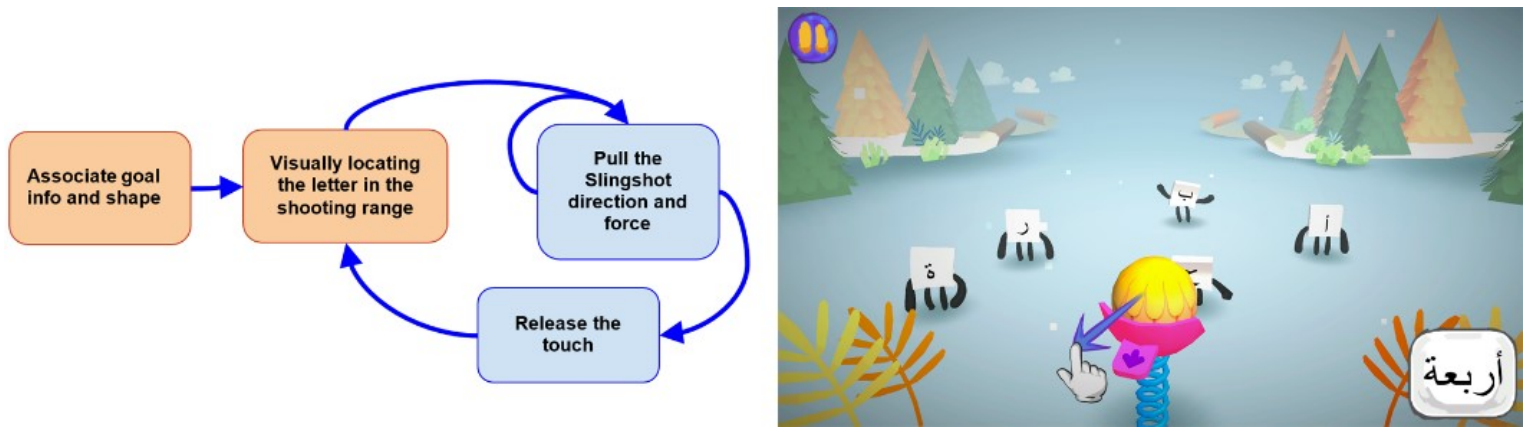

Figure 6: Modified gameplay loop of the mini-game Throw Ball, at the end of the pre-production (left); screenshot of the final version, with a slingshot, in its spelling variation (right)

However, in the rush of production, some changes were not documented. For instance, in another mini-game, Dancing Dots, gameplay changed during the late stages of production, but the gameplay loop was not updated in the documents. However, at the time, we were realizing the final documentation of the game for educators, the gameplay loop was used as a tool of analysis. We were able to create an updated version of the Dancing Dots gameplay loop (figure 7 left) to accompany an illustrated screenshot walkthrough (figure 7 right) comparable to the initial storyboard. 

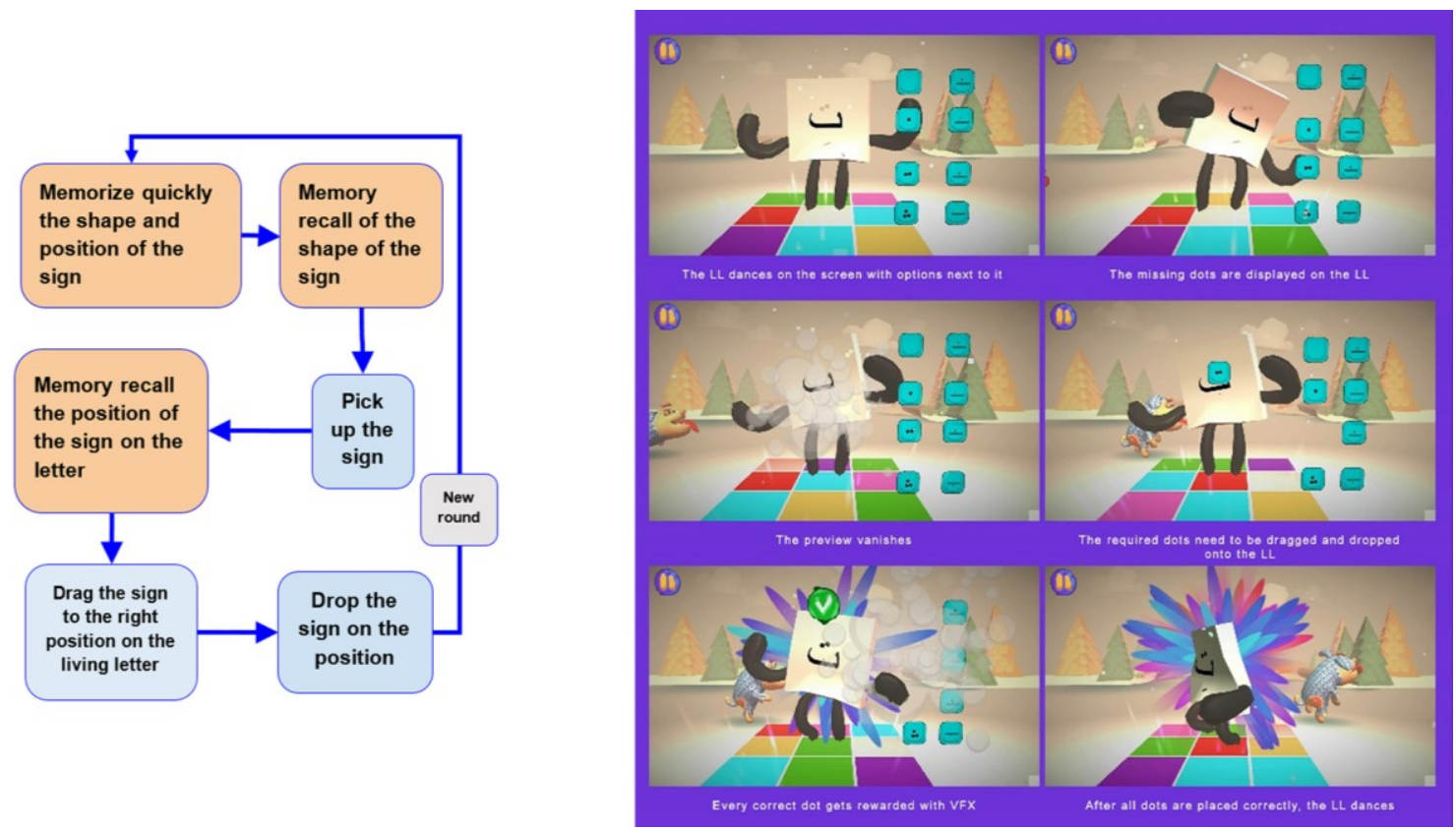

Figure 7: Final analysis of the gameplay loop of the mini-game Dancing Dots (left), and the step by step explanation of the final version of this game (right)

\section{Results from an impact evaluation of Antura and the Letters}

In 2017, a broad impact evaluation was conducted in Jordan. It was organized by an independent impact study agency (Integrated Services Indigenous Solutions) and funded by several organizations (All Children Reading, the Norwegian Ministry of Foreign Affairs, UNICEF). Its results have been published in a report by Koval-Saifi and Plass (2018). During the study, more than 300 children played Antura in daily 45-minute sessions for seven weeks. The EGRA (Early Grade Reading Assessment) literacy evaluation form was administrated before and after the seven-week playing phase to the 366 children playing Antura (treatment group) and to a control group of 383 additional children (control group). Due to the refugee camp context, the attrition between the baseline and the endline was high. The number dropped to 200 for treatment and 202 for control. We should also mention that the Antura treatment group had lower baseline EGRA evaluations than the control group because a majority of these children were from illiterate families (Koval-Saifi and Plass, 2018).

The results of the impact evaluation are positive and demonstrate the progress of the Antura group in literacy, while the control group showed no progress: "the treatment group showed gains in performance from baseline to endline and greater gains in comparison to the control group. Mean scores improved by two to three words/letters for letter sound knowledge, syllable reading, and ORF subtasks. The treatment group showed higher rates of change than the control group from baseline to endline" (Koval-Saifi and Plass, 2018, p. 33). So, despite their disadvantaged family environment, the treatment group progresses (figure 8).

\begin{tabular}{|c|c|c|c|c|c|c|c|c|}
\hline \multirow{2}{*}{ Subtask } & \multirow{2}{*}{ Group Type } & \multicolumn{2}{|c|}{ Baseline } & \multicolumn{2}{|c|}{ Endline } & \multicolumn{2}{|c|}{ Total } & \multirow{2}{*}{$\begin{array}{l}\text { Rate of } \\
\text { Change }\end{array}$} \\
\hline & & Mean & SD & Mean & SD & Gain & SD & \\
\hline \multirow{2}{*}{$\begin{array}{l}\text { Letter Sound } \\
\text { Knowledge }\end{array}$} & Treatment & 7.72 & 14.2272 & 10.31 & 16.9379 & 2.59 & 16.6053 & $34 \%$ \\
\hline & Control & 13.10 & 17.60739 & 13.12 & 18.64871 & 0.02 & 20.48555 & $0 \%$ \\
\hline \multirow{2}{*}{$\begin{array}{l}\text { Syllable } \\
\text { Reading }\end{array}$} & Treatment & 4.42 & 8.47273 & 6.67 & 10.2905 & 2.25 & 6.87183 & $51 \%$ \\
\hline & Control & 7.85 & 11.90235 & 8.44 & 12.59203 & 0.59 & 11.57939 & $8 \%$ \\
\hline \multirow{2}{*}{$\begin{array}{l}\text { Invented } \\
\text { Word } \\
\text { Decoding }\end{array}$} & Treatment & 0.90 & 2.4011 & 1.63 & 3.84714 & 0.73 & 3.15526 & $81 \%$ \\
\hline & Control & 2.54 & 5.74136 & 2.25 & 4.827161 & -0.29 & 5.090929 & $-11 \%$ \\
\hline \multirow{2}{*}{$\begin{array}{l}\text { Oral Reading } \\
\text { Fluency }\end{array}$} & Treatment & 3.42 & 7.32108 & 5.84 & 9.93051 & 2.42 & 6.31632 & $71 \%$ \\
\hline & Control & 6.43 & 11.30546 & 6.46 & 11.1038 & 0.03 & 8.851034 & $0 \%$ \\
\hline
\end{tabular}

Figure 8: Results of the Early Grade Reading Assessment evaluation from Koval-Saifi and Plass (2018) 
The results for the Oral Reading Fluency (ORF), as shown in figure 9, were particularly strong: "results [...] indicate very low fluency rates among both the treatment and control groups. The treatment group read about half the words than the control group at baseline (3.4 correct words per minute (CWPM), compared to 6.4 CWPM). At endline, the treatment group read 5.8 CWPM, versus 6.5 for the control group. While the treatment group read fewer CWPM than the control group, they had higher gains: children in treatment read 2.4 more CWPM at endline, compared to 0.03 more 43 CWPM for the control group (for further analysis, see Section 5.2.2 EGRA Summary Results). The rate of change for this gain was $71 \%$ for the treatment group, as compared to $0 \%$ rate of change for the control" (Koval-Saifi and Plass, 2018, pp. 43-44).

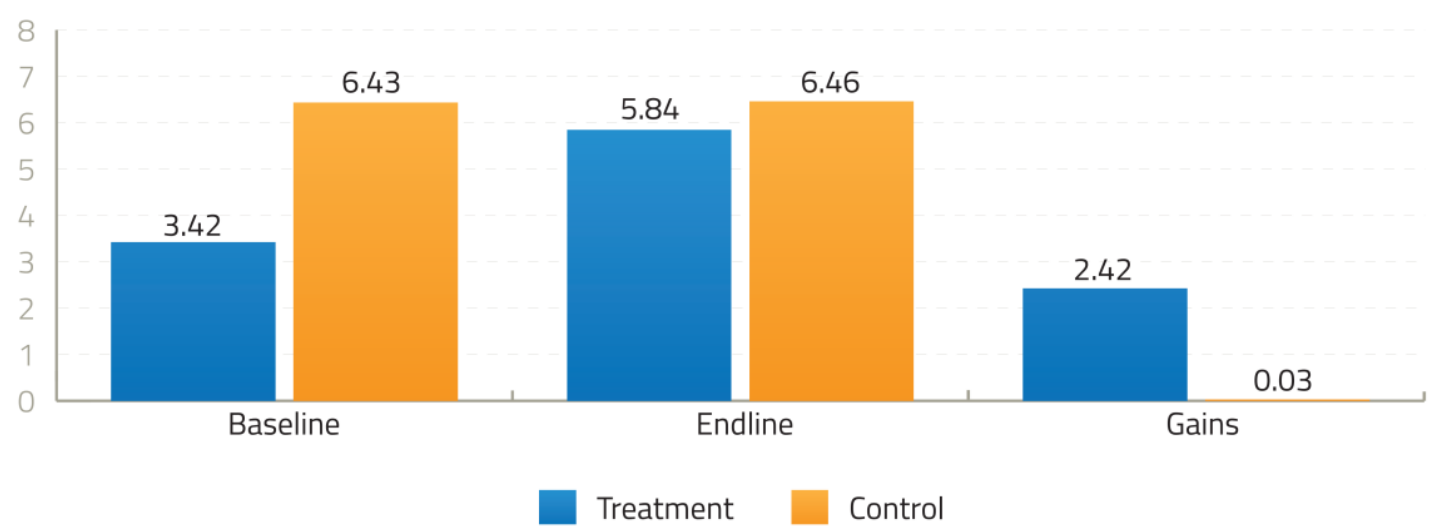

Figure 9: Results of the Oral Reading Fluency evaluation from Koval-Saifi and Plass (2018)

Additionally, qualitative feedback pointed to flaws in the pedagogical structure of the open beta and led the team to reinforce the phoneme and syllable stages in the game. These modifications were integrated in the final version released in March 2018.

The psychosocial impact of playing Antura and the Letters was also evaluated during the Jordan field test. The Strengths and Difficulties Questionnaire (SDQ) was administrated before and after the test period, and shows significant beneficial effects for the Antura players group compared to the control group.

\section{Discussion}

\subsection{Lessons from the use of the gameplay loop methodology in Antura and the Letters}

In the context of the production of Antura and the Letters, the gameplay loop methodology provides insights into the design and an explicit visualization of the weight of ludic and pedagogical actions. It also allows developers to understand the impact of game design propositions during the iterative process of playtests and improvements. One of the limitations of the gameplay loop methodology in the way that it was applied in Antura is the difficulty of classifying actions and players' abilities that are challenged. The vocabulary used to describe actions aren't framed by rules. Future improvements to the gameplay loop methodology may include creating a more precise basic vocabulary to describe these actions, incorporating requirements from other fields. For example, curricular task lists or explicit cognitive abilities named by pedagogical experts could inform the development of such a vocabulary.

Initially, the gameplay loop was used during the early stages of game development. It is not natural in an entertainment game to update this kind of document throughout later stages of production. A game team normally focuses on prototypes and the actual game, and not on updating the content of such documents.

However, in the development of an educational game, such documentation is necessary. The nature of this tool allows designers to use it to retro-engineer different parts of the game, and then to update the gameplay descriptions even months after their design and production.

\subsection{The significance of the gameplay loop methodology for educational game design}

In the beginning of this paper, we identified a gap in the literature on serious game design including the neglect of an important unit of analysis, namely the unfolding of gameplay through players' actions over a relatively short period of time; the lack of a common consideration of game mechanics and learning 
mechanics; and the false separation of playing and learning. In the following, we will outline how the gameplay loop methodology, suggested in this paper and designed specifically for educational games, contributes to the closure of this gap, in other words, what the gameplay loop methodology adds to the field of educational game design.

In accordance with the long-standing theoretical claim that playing and learning cannot and should not be separated (Gee, 2003)-related to the concept of "stealth learning" assuming that players should be "focused not on learning but on playing" (Winn, 2008)-the gameplay loop methodology continuously considers both the target group's potential actions as well as the target group's potential learning. The methodology is thus rooted in traditional approaches to serious game design (and their underlying learning theories) that favor endogenous educational games over exogenous educational games. While exogenous educational games (e.g. edutainment titles such as Math Blaster, Davidson \& Associates, 1983) "separate learning content and game mechanics" and "insert[...] the content to be learned into the preexisting game structure and rules" whereby "[c]ontent is often the only new input, and the learning tends to be limited to reinforcing knowledge recall", endogenous educational games "target more complex learning goals beyond memorization and do so in part by integrating learning content into the structure of the game" (Winn, 2008; see Halverson, 2005). The methodology thereby reacts to one major criticism towards serious games in general and educational games in particular: "the inadequate integration of educational and game design principles" (Arnab et al., 2015, p. 392). Overall, we aspire to achieve a comprehensive merging of game design and instructional design.

In addition to addressing this call to consider both gameplay and learning (derived from digital game-based learning theories), we also comply with a claim by player research and user-centered design: that the player should be considered throughout the development process. In this sense, the gameplay loop methodology is similar to the MDA model used for the design of entertainment games, which also strongly emphasizes the player's perspective (Hunicke, LeBlanc and Zubek, 2004).

The gameplay loop methodology offers an approach to design that focuses on both game mechanics and learning mechanics. It allows a close monitoring of the interconnections between gameplay and learning at the micro level of players' actions. In contrast to other serious game design methodologies, it is particularly catered to cover educational games. We assume, however, that in practice the gameplay loop methodology should be complemented by other approaches. As the methodology takes the view of the game design department, other more holistic frameworks, such as Mitgutsch and Alvarado's (2012) SGDA framework, could be applied to consider the perspective of other departments (such as the art department) in order to achieve a well-rounded game that is as aesthetically and mechanically appealing as commercial off-the-shelf games and allows its players a learning experience related to an educational domain beyond the game itself, building on the unique learning possibilities of play and games.

\section{Conclusion}

Over the course of this paper, we have suggested the gameplay loop methodology as a valuable tool for the design of educational games. Using examples from the design and production of Antura and the Letters, a literacy game for Arabic refugee children, we have demonstrated the practical usefulness of this methodology - with a focus on gameplay and learning - for educational game design. We have also described how the gameplay loop methodology is situated in a broader educational game design approach-including the application of methods from player-centered game design as well as the consideration of knowledge from domain-specific didactics (in this case Arabic language pedagogy) which is rarely emphasized in other educational game design methodologies. Overall, we have argued that the methodology contributes to the closure of a gap in the literature on methodologies for the practice of educational game design because it focuses on the unfolding of gameplay through players' actions over a relatively short period of time as a unit of analysis, considers game mechanics and learning mechanics in their interdependencies, and thus merges playing and learning on a micro level. We then summarized results from an impact study, which show that the desired union of playing and learning has been successful in the case of Antura and the Letters.

However, the empirical evidence for the usefulness of the gameplay loop methodology when it comes to the design of educational games that initiate a unification of playing and learning is insofar limited as the presented case study represents only a particular form of educational games, i.e., a series of meaningfully connected mini-games relying on cognitive theories of learning. Future empirical studies should verify the 
usefulness of the methodology across genres and pedagogical approaches. They should furthermore go beyond the single case study design as well as systematically compare the methodology's design processes and outcomes with those of other methodologies.

Future conceptual works should, among other things:

- create a more standardized and comprehensive vocabulary to describe players' actions and learning-building on knowledge and language from disciplines such as educational sciences, learning sciences, and cognitive science as well as particular curricula from different areas of education, starting for instance with Bloom's taxonomy of educational objectives (see Bloom and Committee of College and University Examiners, 1964, and Anderson et al., 2001);

- apply the gameplay loop methodology to different genres of digital (educational) games as well as to serious games in general;

- outline ways in which the methodology can be combined with and/or embedded in other more holistic frameworks (including the perspectives of game artists and game programmers);

- $\quad$ and reconstruct instructional strategies and learning theories that can be found in games designed with the methodology (which might be supported by the nature of the methodology) and subsequently add features to the methodology that allow designers to distinguish between and reflect on different instructional strategies and learning theories.

\section{Acknowledgements}

We would like to thank Elaine Chen and Alexandra Petrus for their valuable editorial assistance in the preparation of this article. This research project received funding from the Norwegian Ministry of Foreign Affairs as part of EduApp4Syria innovation competition. The impact test evaluation was supported by All Children Reading and UNICEF.

\section{References}

Anderson, L.W., Krathwohl, D.R., Airasian, P., Cruikshank, K., Mayer, R., Pintrich, P., Raths, J. and Wittrock, M., 2001. A taxonomy for learning, teaching and assessing: A revision of Bloom's taxonomy, Longman Publishing, New York.

Arnab, S. and Clarke, S., 2016. Towards a trans-disciplinary methodology for a game-based intervention development process. British Journal of Educational Technology, 48(2), pp. 279-312.

Arnab, S., Lim T., Carvalho, M.B., Bellotti, F., de Freitas, S., Louchart, S. et al., 2015. Mapping learning and game mechanics for serious games analysis, British Journal of Educational Technology, 46(2), pp. 391-411.

Ávila-Pesántez, D., Rivera, L. A. and Alban, M. S., 2017. Approaches for Serious Game Design: A Systematic Literature Review, Computers in Education Journal, 8(3), pp. 1-11.

Becker, K., 2006. Design Paradox: Instructional Games. Proceedings of International Conference on the Future of Game Design and Technology 2006. The University of Western Ontario, London, October 10-11 2006.

Becker, K., 2011. The magic bullet: a tool for assessing the evaluating learning potential in games, International Journal of Game-Based Learning, 1(1), pp.19-31.

Bloom, B. S. and Committee of College and University Examiners., 1964. Taxonomy of educational objectives. Vol. 2. New York: Longmans, Green.

Buchanan, L., Wolanczyk, F. and Zinghini, F., 2011. Blending Bloom's taxonomy and serious game design, Proceedings of the 2011 International Conference on Security and Management. Las Vegas, 18-21 July 2011. Las Vegas: CSREA Press.

Carvalho, M. B., Bellotti, F., Berta, R., De Gloria, A., Sedano, C. I., Hauge, J. B., Hu, J. and Rauterberg, M., 2015. An activity theory-based model for serious games analysis and conceptual design, Computers \& Education, 87, pp. 166-181.

Cologne Game Lab/TH Köln, Video Games Without Borders and Wixel Studios (2017) Antura \& the Letters - Arabic [Android] [iOS] (March 2017) [PC] (July 2017), Video Game Without Borders, Sant Cugat del Valles.

Davidson \& Associates (1983) Math Blaster! [C64] [PC], Apple, Atari.

De Freitas, S. and Oliver, M., 2006. How can exploratory learning with games and simulations within the curriculum be most effectively evaluated?. Computers \& Education, 46(3), pp. 249-264.

Fullerton, T., 2014. Game design workshop: A playcentric approach to creating innovative games. Boca Raton/London/New York, NY: CRC Press.

Gee, J.P.,2003. What video games have to teach us about learning and literacy. New York: Palgrave Macmillan, New York.

Guardiola, E., 2016. The Gameplay Loop: a Player Activity Model for Game Design and Analysis, Proceedings of the ACE 2016, 13th International Conference on Advances in Computer Entertainment Technology. Osaka, Japan, 9-12 November 2016. New York: ACM.

Guardiola, E., Czauderna, A. and Samur, Y., 2019. Player-Centred Educational Game Design. The Case of Antura and the Letters, In: A. Bresges and A. Habicher, ed. 2009. Digitalisierung des Bildungssystems. Aufgaben und Perspektiven für die Lehrerlnnenbildung. Münster: Waxmann. 
Gunter, G., Kenny, R. and Vick, E., 2006. A case for a formal design paradigm for serious games. The Journal of the International Digital Media and Arts Association, Vol. 3, pp. 93-105.

Halverson, R., 2005. What can K-12 school leaders learn from video games and gaming?. Innovate Journal of Online Education, 1(6).

Hodent, C., 2017. The gamer's brain. How neuroscience and UX can impact video game design, CRC Press, Boca Raton/London/New York, NY.

Hunicke, R., LeBlanc, M. and Zubek, R., 2004. MDA: A Formal Approach to Game Design and Game Research, Proceedings of the Challenges in Game AI Workshop, Nineteenth National Conference on Artificial Intelligence. Palo Alto, United States, 25-29 July 2004. Palo Alto: AAAI Press.

Kelle, S., Klemke, R. and Specht, M., 2011. Design Patterns for Learning Games. International Journal of Technology Enhanced Learning, 3(6), pp. 555-569.

Kiili, K., 2010. Call for learning-game design patterns, In: F. Edvardsen and H. Kulle, ed. 2010. Educational games: design, learning and applications. Hauppauge, NY: Nova Science Pub Inc, pp. 299-311.

Koval-Saifi, N. and Plass, J., 2018. Antura and the Letters, Impact and Technical Evaluation [pdf] Washington, D.C., USA: World Vision. Available at:<https://allchildrenreading.org/resources/antura-letters-impact-technical-evaluation/>.

Lameras, P., Arnab, S., Dunwell, I., Stewart, C., Clarke, S. and Petridis, P., 2017. Essential features of serious games design in higher education: Linking learning attributes to game mechanics, British Journal of Educational Technology, 48(4), pp. 972-994.

Lim, T., Louchart, S., Suttie, N., Ritchie, J., Aylett, R., Stanescu, I.A. et al., 2013. Strategies for effective digital games development and implementation, In: Y. Baek and N. Whitton, ed. 2013. Cases on digital game-based learning: methods, models, and strategies. Hershey: Information Science Reference. Ch.10.

Mitgutsch, K. and Alvarado, N., 2012. Purposeful by Design. A Serious Game Design Assessment Model, FDG 2012, FDG '12 Proceedings of the International Conference on the Foundations of Digital Games. Releigh, North Carolina, 29 May-01 June 2012. New York: ACM.

Niantic, 2016. Pokémon Go. [iOS \& Android game] San Francisco: Niantic.

Norman, D. A., 1990. The design of everyday things. New York: Basic Books.

Salen, K. and Zimmerman, E., 2003. Rules of play: Game design fundamentals. Cambridge, MA: MIT Press.

Winn, B., 2008. The Design, Play, and Experience Framework, In: R. Ferdig, ed. 2008. Handbook of Research on Effective Electronic Gaming in Education, Vol. 3, Hershey: IGI Global Publication. 